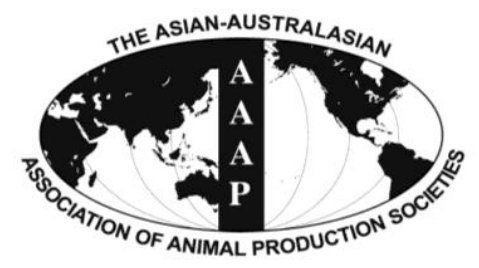

Asian Australas. J. Anim. Sci.

Vol. 26, No. 9 : 1247-1254 September 2013

http://dx.doi.org/10.5713/ajas.2013.13042

www.ajas.info

pISSN 1011-2367 elSSN 1976-5517

\title{
Effects of Sheng Hua Tang on Uterine Involution and Ovarian Activity in Postpartum Dairy Cows
}

\author{
K. H. Lee, ${ }^{1,2, a}$, Y. T. Lee, ${ }^{1, a}$, T. C. Chen ${ }^{3}$, C. C. Yeh ${ }^{4}$, J. Y. Chen ${ }^{2}$, L. Y. Liu' ${ }^{5}$ and C. H. Chi' ${ }^{1, *}$ \\ ${ }^{1}$ Department of Veterinary Medicine, National Taiwan University, Taipei, 10617, Taiwan
}

\begin{abstract}
The effects of Sheng Hua Tang (SHT) on uterine involution and ovarian activity were investigated in postpartum dairy cows. SHT $(70 \mathrm{~g})$ was given to dairy cows $(\mathrm{n}=10)$ to evaluate its effects for five days from the first postpartum day. Postpartum cows fed with a basal diet without SHT were used as the control group $(\mathrm{n}=10)$. Ultrasounds and blood tests were recorded for four weeks from postpartum day seven with a 3-d interval. The results showed that the areas and diameters of endometria were significantly $(p<0.01)$ reduced in the group that received SHT compared to the control group on the seventh postpartum day. The group that received SHT had an intrauterine fluid volume mean of $1.2 \pm 0.6 \mathrm{~cm}^{3}$, which was significantly lower than that of the control group, $2.3 \pm 0.8 \mathrm{~cm}^{3}$ $(\mathrm{p}<0.01)$ on the 13th postpartum day. In addition, the uterine tension score was a mean of $1.0 \pm 0.0$ in the group that received SHT, which was also significantly lower than that of the control group, $1.5 \pm 0.5(\mathrm{p}<0.01)$ on the 19th postpartum day. Taken together, the Chinese herbal medicine remedy, SHT, promoted uterine involution and ovarian activity in postpartum dairy cows. (Key Words: Chinese Herbal Medicine, Sheng Hua Tang, Ultrasonography, Fertility, Dairy Cows)
\end{abstract}

\section{INTRODUCTION}

Chinese herbal medicines have been used by postpartum nurses, in humans, for hundreds of years. The ancient Chinese book noted that delivery of a baby exhausts a woman's physical health and that Sheng Hua Tang (SHT) helps to promote blood flow, resolve blood stasis, warm the meridians/channels, alleviate pain, and eliminate lochia (Bensky and Barolet, 1993). Chinese women commonly use SHT after giving birth. In Taiwan, more than $80 \%$ of women take SHT postpartum (Chuang et al., 2009). The formula of SHT consists of five ingredients including: Radix Angelicae Sinensis (Danggui), Ligustici Rhizoma (Chuan Xiong), Semen Persicae (Tao Ren), Zingiberis Rhizoma (Pao Jiang), and Glycyrrhizae Radix (Zhi Gan

\footnotetext{
* Corresponding Author: C. H. Chi. Tel: +886-2-27323817, Fax: +886-2-23661475, E-mail: chie@ ntu.edu.tw

${ }^{2}$ Hsin-Chu Branch Station, COA- TRI, Miao-li 36848, Taiwan.

${ }^{3}$ Department of Biotechnology, Asia University, Taichung, 41354, Taiwan.

${ }^{4}$ Department of Medicine, Tzu Chi University, Hualien, 97004, Taiwan.

${ }^{5}$ Department of Plant Science, National Pingtung University of Science and Technology, Pingtung, 91201, Taiwan.

${ }^{a}$ These authors contributed equally.

Submitted Jan. 15, 2013; Accepted Apr. 8, 2013; Revised May 16, 2013
}

Cao). Radix Angelicae Sinensis is the major ingredient of SHT. Angelicae polysaccharide isolated from Radix Angelicae Sinensis may directly or indirectly stimulate the bioactivity of bone marrow macrophages in the hematopoietic inductive microenvironment to accelerate the synthesis and secretion of hematopoietic regulation factors at the gene and protein levels (Wang and Zhu, 1996; Wang et al., 2004; Li and Wang, 2005). These beneficial hematopoietic effects may also be mediated by the antiinflammatory properties of Radix Angelicae Sinensis (Hu et al., 1991).

In dairy cows, reproductive problems usually occur during calving and post parturition. Reestablishment of postpartum reproductive efficiency involves the resumption of normal ovarian activity and uterine involution. Uterine involution involves the contraction of the uterus, sloughing of the caruncles and regeneration of the endometrium (Gier and Marion, 1968). Complete uterine involution can be observed when the size of the uterus shrinks to its pregravid state (Hussain and Daniel, 1991). In previous reports, rectal ultrasonography was successfully used to evaluate uterine involution in postpartum dairy cows (Ginther, 1998). The recovery of endometrial areas as well as scored intrauterine fluid volumes was used for indexing of uterine involution (Hu et al., 1991; Mateus et al., 2002). The first 
ovarian cycle after parturition is shorter than the normal oestrous cycle in cows; the first postpartum ovulation occurs 17 to $34 \mathrm{~d}$ after calving in most dairy cows (Kindahl et al., 1999). The first ovulation is generally at $19 \pm 1 \mathrm{~d}$ postpartum in dairy cows milked twice daily, and the earliest time to ovulation is 10 to $15 \mathrm{~d}$ after parturition (Youngquist, 1997). Early postpartum ovulation and pregnancy within three estrus cycles can improve the fertility of dairy cows (Thatcher and Wilcox, 1973; Benmrad and Stevenson, 1986). The appearance of the first significant progesterone rise $(\geq 1 \mathrm{ng} / \mathrm{mL})$ indicates the resumption of ovarian activity (Stevenson, 1997; Opsomer et al., 2000). In many reports of endometritis and uterine infections, lutein serves as the target of active ovarian response (Peter and Bosum, 1987; Gilbert et al., 1990; Huszenicza et al., 2005).

In most dairy cows, uterine involution is completed 4 to $5 \mathrm{wks}$ postpartum; the earliest time for uterine involution is about three weeks postpartum. If the fetal membranes are retained and/or endometritis develops in the uterus of a cow, the time to uterine involution can be prolonged for 30 to 50 $\mathrm{d}$ (Lindell et al., 1982). Because a large volume of necrotic tissue is produced in a fluid medium (lochia) during the process of normal involution, the postpartum uterine cavity can be contaminated by bacteria. Bacteria can be naturally cleared from the uterus in the first two to three weeks after calving in most healthy cows (Bondurant, 1999). If dairy cows are severely infected with bacteria, antibiotics and hormone-prepared drugs can be used for treatment. However, the problems of drug retention and resistance are concerns. In many reports, lutein was used for the treatment of endometritis and uterineinfections (Peter and Bosu, 1987; Gilbert et al., 1990; Huszenicza et al., 2005).

In this study, SHT was used to treat the uterine diseases of postpartum dairy cows in China. The scientific evidence supporting SHT activity is still limited. In this investigation, ultrasonography was used to study the uterus and blood testing to determine the concentration of plasma progesterone to evaluate the effects of SHT on the process of uterine involution and ovarian activity in postpartum dairy cows.

\section{MATERIALS AND METHODS}

\section{Experimental animals}

Twenty Holstein-Friesian cows, 2 to 8 yrs old (average body weight $586 \mathrm{~kg}$; 1 st lactation: $\mathrm{n}=4$, 2nd lactation: $\mathrm{n}=$ 6, 3rd lactation: $n=6$, and 4th lactation: $n=4$ ), were used in this study. The cows did not receive any treatment during the month prior to the beginning of the experiment. These cows were housed in the animal shed at the farm of Hsinchu Branch Station, COA-TLI, Hsinchu, Taiwan, under identical environmental conditions. The use of animals was approved by the Institutional Animal Care and Use Committee (IACUC). All cows were normally calved without periparturient diseases, such as dystocia, uterine prolapse and retained fetal membranes, and housed in freestalls.

\section{Sheng Hua Tang treatment}

According to our pretrial results showed that cows fed with $30 \mathrm{~g}(\mathrm{n}=3)$ or $50 \mathrm{~g}(\mathrm{n}=3)$ of SHT powder for five days no positive effects in uterine involution of postpartum cows. However, it showed positive effects on cows fed with $70 \mathrm{~g}(\mathrm{n}=3)$ of SHT powder (data not shown). So, in this study, 20 lactating postpartum Holstein-Friesian cows were randomly assigned to 2 groups, control $(n=10$, fed with basal diet) and treatment $(n=10$, fed with basal diet and SHT herb powder, $70 \mathrm{~g}$ per $\mathrm{d}$ ). The $70 \mathrm{~g}$ of SHT powder (Koda Pharmaceutical Ltd., Taoyuan, Taiwan) was dissolved in $300 \mathrm{~mL}$ water for feeding. During the dry period (30 d of prepartum) cows were fed with $4 \mathrm{~kg}$ concentrate and $4 \mathrm{~kg}$ alfalfa hay daily, and Bermuda hay was accessed freely. After calving, the amount of concentrate fed was based on the milking level using a 1:3 concentrate to milk ratio (upper limit was $10 \mathrm{~kg}$ of concentrate). The concentrate composition is shown in Table 1. Alfalfa hay, supplied for roughage, had an upper limit of $8 \mathrm{~kg}$, while Bermuda hay was accessed freely. The nutrient supply followed NRC (1989). Mineral salt and water were supply ad libitum. The individuals of the treatment group orally received SHT for five days starting from the postpartum $\mathrm{d} 1$ to $\mathrm{d} 5$.

Table 1. The composition of experimental concentrate

\begin{tabular}{lc}
\hline Ingredient (DM basis) & $\%$ \\
\hline Corn & 66.5 \\
Soybean meal & 20 \\
Wheat bran & 6 \\
Molasses & 5 \\
Dicalcium phosphate & 1 \\
Salt & 0.5 \\
Sodium bicarbonate & 0.6 \\
Premix* & 0.4 \\
Total & 100 \\
Analyzed value & \\
Dry matter $(\%)$ & 89.7 \\
Crude protein $(\%)$ & 16 \\
Crude fat $(\%)$ & 7 \\
Crude fiber $(\%)$ & 3.2 \\
Crude ash $(\%)$ & 7.3 \\
NDF $(\%)$ & 35.4 \\
ADF $(\%)$ & 42.4 \\
Gross energy $(\mathrm{MJ} / \mathrm{kg})$ & 17.1 \\
\hline
\end{tabular}

* Per kg of premix contain: Vitamin A, 10,000,000 IU; Vitamin E, 70,000 IU; Vitamin $\mathrm{D}_{3}, 1,600,000 \mathrm{IU} ; \mathrm{Fe}, 50 \mathrm{~g} ; \mathrm{Mn}, 40 \mathrm{~g}$; Cu, $10 \mathrm{~g}$; Zn, $40 \mathrm{~g}$; Se, $0.1 \mathrm{~g} ; \mathrm{Co}, 0.1 \mathrm{~g}$. 


\section{Ultrasonography}

The reproductive organs of cows were examined for 4 wks from the postpartum $\mathrm{d} 7$ at a 3 -d interval by the same veterinarian. Ultrasonography was conducted by a $5 \mathrm{MHz}$ transrectal linear transducer (SonoSite ${ }^{\circledR}$ TITAN $^{\mathrm{TM}}$, SonoSite, Inc., USA) to assess uterine characteristics of the gravid and nongravid horns. Diameters and areas of the endometria at the base of each uterine horn (approximately $5 \mathrm{~cm}$ anterior the uterine body) were measured and recorded by crosssectional images (Okano and Tomizuka, 1987). If the structure of the scanned images was not spherical, the diameters of two $90^{\circ}$ dimensions of an uterine horn were averaged to obtain the diameter values (Sheldon et al., 2002). The intrauterine fluid volumes were scored in a 0 to 3 scale: 0 represents no fluid and 1 to 3 represent the increasing fluid volumes in the uterine hornsas the previously described (Mateus et al., 2002). The uterine tonicities were scored in a 1 to 3 scale: 1 represents the uteruses with high tonicity, 2 represents the uteruses with moderate tonicity and 3 represents the flaccid uteruses (Melendez et al., 2004). The presences of luteal tissues in gravid and ipsilateral ovaries were also recorded by ultrasonography.

\section{Progesterone assay}

Blood samples were collected following the procedure described previously (Paape et al., 1972) with modifications. Briefly, $9 \mathrm{~mL}$ of blood were collected aseptically from the jugular vein using an 18 gauge needle into a vacuum $\mathrm{K}_{3}$ EDTA tube (Becton Dickinson Vacutainer System, Franklin Lakes, NJ, USA) as aforementioned periods. The tubes were centrifuged at $2,200 \times \mathrm{g}$ for $10 \mathrm{~min}$ to harvest the plasma and stored at $-20^{\circ} \mathrm{C}$ until it was analyzed for progesterone. Progesterone was measured in duplicate for each sample with a hormonal chemiluminescence assay (CIA) (Galbreath, 2008) by Union Clinical Laboratory, Taipei. The measuring range is 0.5 to $60 \mathrm{ng} / \mathrm{mL}$.

\section{Statistical analysis}

The results were presented as mean \pm SEM. Statistical comparisons between control and experiment groups were performed using student's $t$ test for the endometrial area, diameter of horn, intrauterine fluid volume and uterine tension score. The appearance of the first significant progesterone rise $(\geq 1 \mathrm{ng} / \mathrm{mL})$ indicating the resumption of ovarian activity. Wilcoxon rank sum test was used for twogroup comparisons of days of ovulation postpartum. A p-value of 0.05 or less was considered statistically significant (SAS, 2002).

\section{RESULTS}

Effects of Sheng Hua Tang treatment on the areas and

\section{diameters of the endometria}

The diameters of two $90^{\circ}$ dimensions of the uterine horns, a spot to b spot, was the minor axis, and c spot to $d$ spot was the major axis, Figure 1; they were measured and averaged to obtain values for the diameters. The average endometrial area of the gravid horns, in the SHT-treated cows, was approximately $8.3 \mathrm{~cm}$ smaller $(\mathrm{p}<0.01)$ than that of the control group on day seven postpartum (Figure 2A). The endometrial diameters of the gravid horns were also reduced significantly on day seven $(\mathrm{p}<0.01)$ and $\mathrm{d} 16$ postpartum $(\mathrm{p}<0.05)$ in the SHT-treated group (Figure 3A). However, the endometrial areas and diameters of the nongravid horns had no significant differences in both experimental and control groups (Figure 2B, and Figure 3B). The results showed that treatment with SHT led to earlier uterine recovery in the cows.

\section{Effects of Sheng Hua Tang treatment on the intrauterine fluid volume and uterine tonicity}

The measurements of the intrauterine fluid volumes are shown in Figure 4. The scores for the intrauterine fluid volume in the SHT-treated group were significantly lower than for the control group at 7, $10(\mathrm{p}<0.05)$, and $13 \mathrm{~d}$ postpartum $(\mathrm{p}<0.01)$ (Table 2). Fluid in the lumen of the uterine horns was decreased and had a score of 0 on d 25 and 19 postpartum in the control and experimental groups, respectively. The recovery of uterine tonicity in the SHTtreated group was earlier than in the control group. The score for uterine tonicity in the SHT-treated group was significantly lower than in the control group on d 19

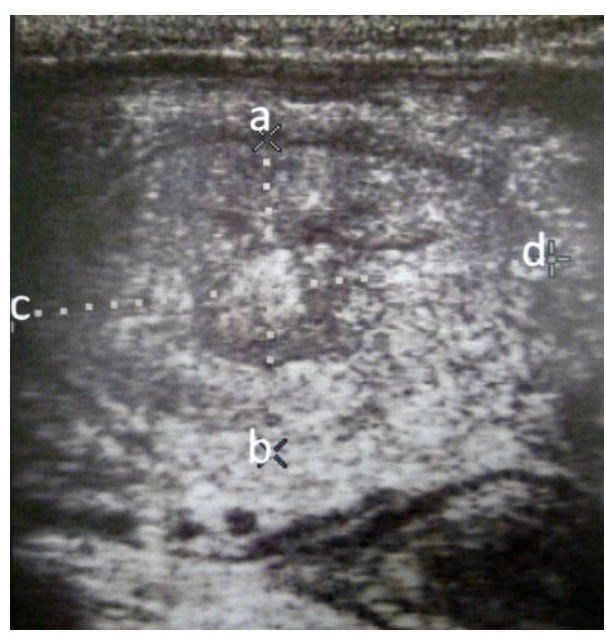

Figure 1. Ultrasonogram of endometria in dairy cows. Diameters and areas of the endometria at the base of each uterine horn (approximately $5 \mathrm{~cm}$ anterior the uterine body) were measured and recorded by cross-sectional images. Note: If the structure of the scanned images was not spherical, the diameters of two $90^{\circ}$ dimensions (a spot to b spot is the minor axis, $\mathrm{c}$ spot to $\mathrm{d}$ spot is the major axis) of uterine horns were averaged to obtain the values of diameters. 


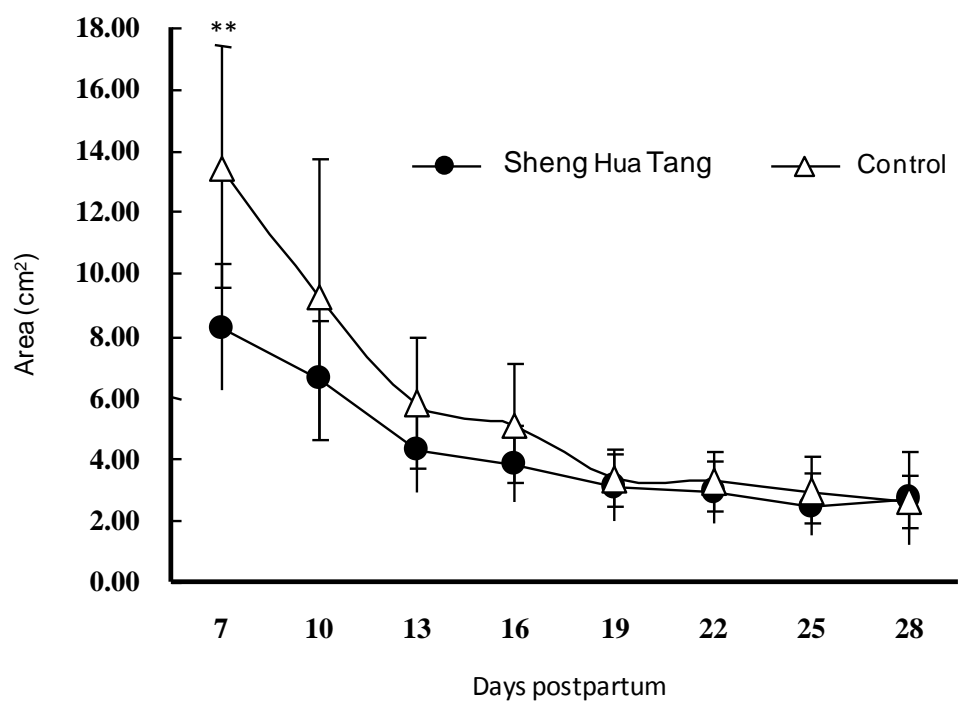

(A)

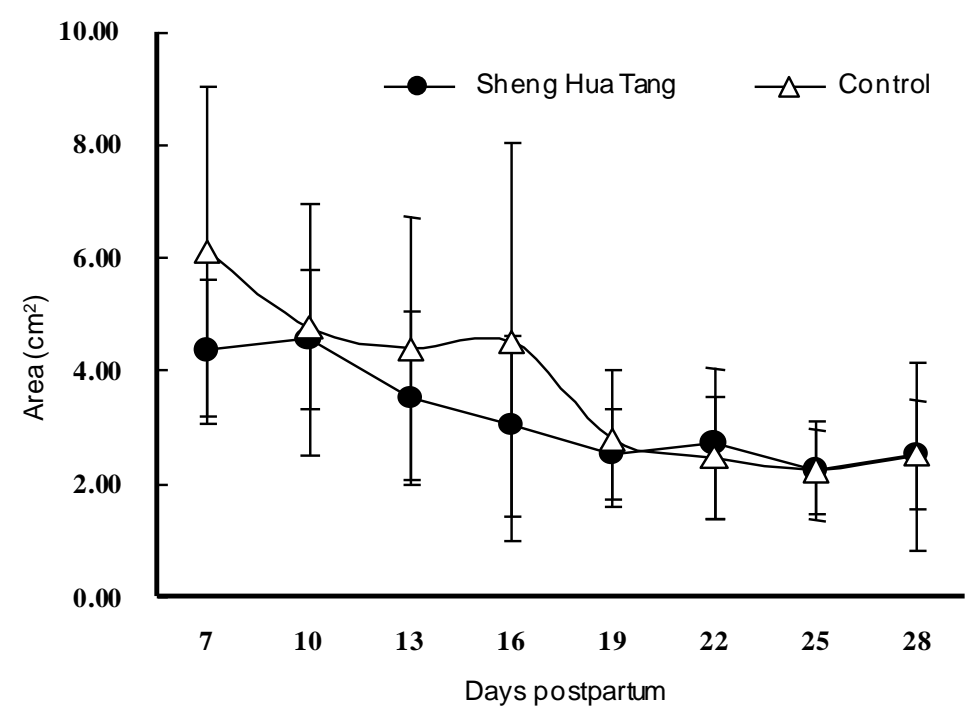

(B)

Figure 2. Effects of Sheng Hua Tang treatment on involutionary progress curves for endometrial areas of uterine horn in postpartum dairy cows. Means \pm SE $(n=10)$. (A) The endometrial area of gravid uterine horn was obviously reduced in the Sheng Hua Tangreceiving group than the control group on the 7th d postpartum. ** Means differ significantly between groups $(\mathrm{p}<0.01)$; (B) The endometrial area of nongravid uterine horn, there were no significant differences in both experimental and control groups.

$(\mathrm{p}<0.01)$ (Table 2). The uteri of all cows receiving SHT had the highest tonicity (score $=1$ ) on $\mathrm{d} 19$ postpartum. However, the uterine tonicity of all control cows was completely recovered on $\mathrm{d} 28$ postpartum.

\section{Effect of Sheng Hua Tang treatment on the progesterone and first ovulation}

Ultrasound of the corpus luteum and the concentration of plasma progesterone $(\geq 1.0 \mathrm{ng} / \mathrm{mL})$ were used to detect the first ovulation as an indication for the resumption of ovarian activity. Table 3 shows that ovarian activity resumed in six of the SHT-treated cows $(60 \%)$ on $d 19$ postpartum. At the same time, four cows $(40 \%)$ in the control group were detected to have resumption of ovarian activity. The results showed that the first ovulation was earlier $(p=0.06)$ in the SHT-treated cows than in the control group.

\section{DISCUSSION}

SHT is a well known traditional Chinese medicine therapeutic formula for improving uterine contraction for the discharge of blood, dead tissue and mucus (Bensky et al., 1993). SHT had been shown to improve the recovery of patient with incomplete miscarriage (Cao et al., 2008) or vaginal hemorrhage resulted from abortion procedures 


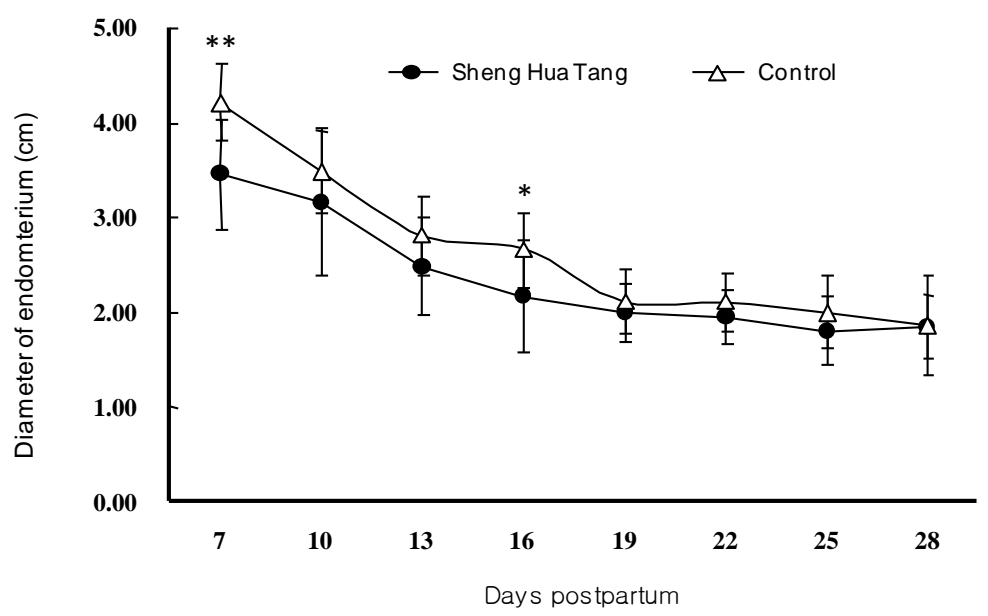

(A)

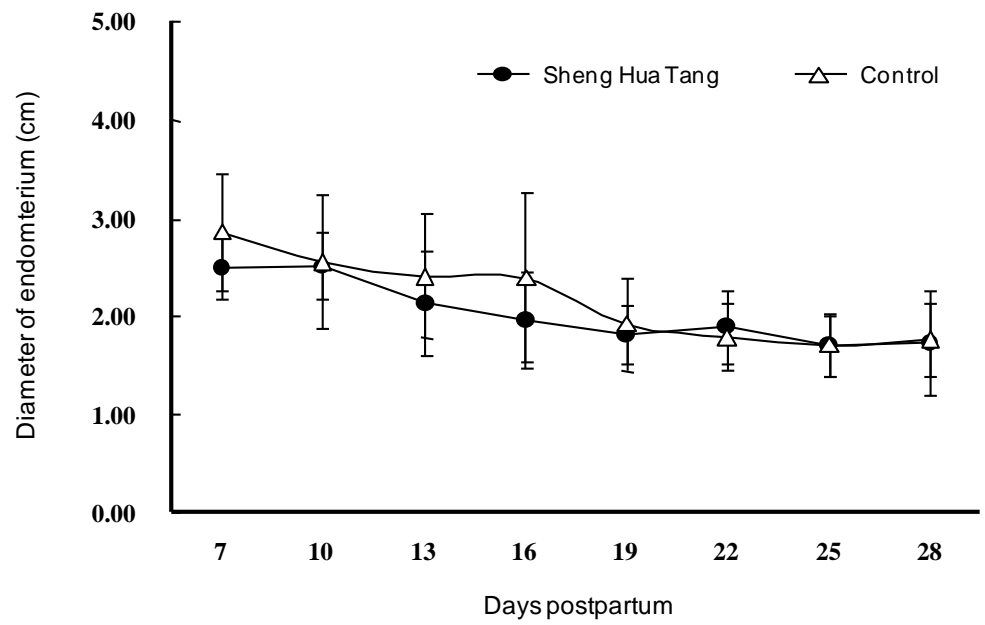

(B)

Figure 3. Effects of Sheng Hua Tang treatment on involutionary progress curves for endometrial diameter of uterine horn in postpartum dairy cows. Means \pm SE $(n=10)$. (A) The endometrial diameter of gravid uterine horn was obviously reduced in the Sheng Hua Tangreceiving group than the control group on the 7th and 16th d postpartum. * Means differ significantly between groups ( $<<0.05$ ); ** Means differ significantly between groups $(\mathrm{p}<0.01)$; (B) The endometrial diameter of nongravid uterine horn, there were no significant differences in both experimental and control groups.

(Zhao et al., 2008). In dairy cows, myometrial contractility plays a major role in clearing lochial debris from the uterus after calving (Slama et al., 1991; Hirsbrunner et al., 2002). Normal myoelectrical activity of the uterus is greater during calving and decreases significantly around seven to nine days postpartum (Gajewski and Faundez, 1992; Gajewski et al., 1999). SHT had also been shown to have similar effects in animal models. These effects include increased myoelectric activity of uterine muscles in rabbits (Hong et al., 2003), and the induction of uterus contraction in mice (Zhao et al., 2003). The positive effects of SHT on uterine involution and ovarian activity, in postpartum dairy cows, have been demonstrated in this study.

Ultrasonography is a simple method to use for the diagnosis uterine involution in dairy cows. The endometrial diameters and areas of gravid horns as well as the intrauterine fluid volumes were significantly reduced on $\mathrm{d} 7$ postpartum in the experimental group $(\mathrm{p}<0.01)$ compared to the control group. These findings indicate that SHT promoted myometrial contractility after calving. Complete uterine involution was detected in all SHT-treated and control cows two to four weeks postpartum, as reported in previous studies (Hussain and Daniel, 1991; Kindahl et al., 1999). In 2011 (Ho et al.) showed that when SHT was used in treating postpartum women, it can increase the contractile activity of the uterus, and also aid the uterus in returning to its anteverted position. However, there was no significant difference observed in the endometrial areas and diameters of the non-gravid uteri of the experimental and control cows. These findings suggest that the non-gravid horns did not completely expand and were less injured during delivery in spite of bacterial contamination. 


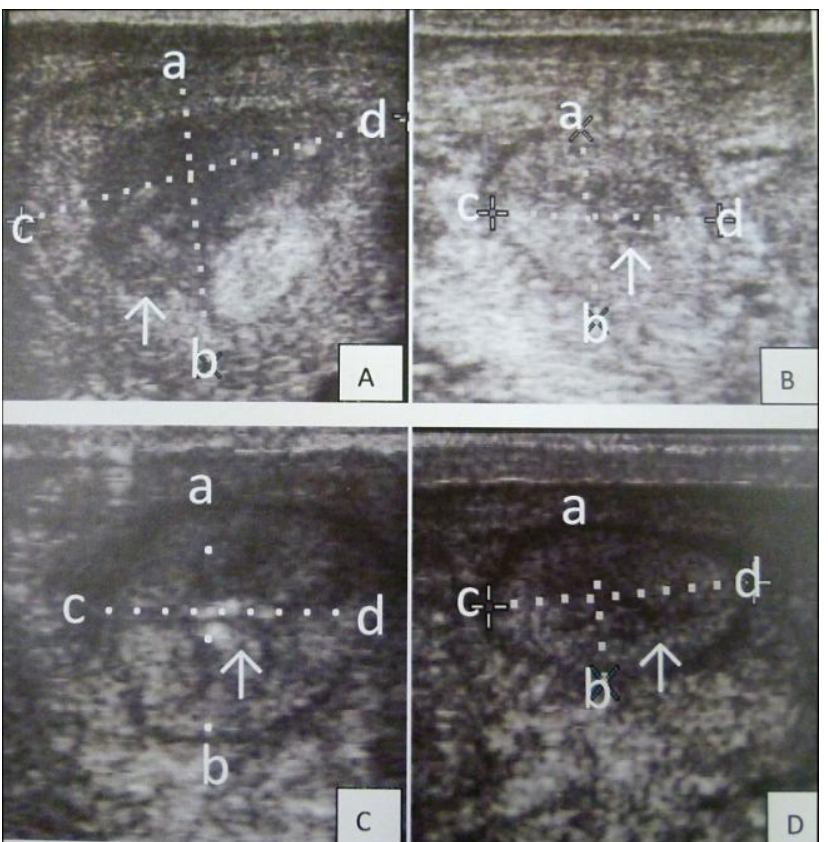

Figure 4. Ultrasonogram of intrauterine fluid volumes in postpartum cows treated with Sheng Hua Tang. The intrauterine fluid volumes were scored in a 0 to 3 scale: 0 represents no fluid and 1 to 3 represent the increasing fluid volumes in the uterine horns. Indicates a-b-c-d regarding the scope is the endometrium, the arrow for the intrauterine fluid; A: In massive intrauterine fluid, score $=3$; B: In quantity intrauterine fluid, score $=2$; C: In few intrauterine fluid, score $=1$; D: None intrauterine fluid, score $=0$.

Previous studies reported that approximately 80 to $100 \%$ of cows may be found to have bacterial contamination in the uterus during the first two weeks postpartum (Paisley et al., 1986; Dohmen et al., 1995;
Sheldon et al., 2004). Due to the promotion of uterine involution by SHT and early discharge of uterine fluid there was no pus discharged from the vagina. On the other hand, uterine tonicity is usually reduced due to damage to the uterus during calving. The uterine tonicity recovered on $\mathrm{d}$ 19 postpartum $(\mathrm{p}<0.01)$ in the SHT-treated group, earlier than the control group in this study.

The resumption of ovarian activity is crucial for subsequent fertility (Darwash et al., 1997; Roch et al., 2000). Ovulation within three weeks postpartum might be an early index for recovery of normal ovarian function and subsequent reproductive performance in high producing dairy cows (Kawahima et al., 2006). The first ovulation occurred in four cows treated with SHT on d 16 postpartum; this was earlier than in the control cows. There were more experimental cows $(70 \%)$ with their first ovulation than control cows $(50 \%)$ before d 28 postpartum. The results suggest that SHT aids in the resumption of ovarian activity. The cows were randomly selected and fed with the same diet at the same farm. All cows in the experimental and control groups, without periparturient insults and uterine infection, were examined clinically by ultrasound and during the first four weeks of postpartum. The occurrences of other disorders, such as milk fever or ketosis, were not observed for all the cows during the period of the experiment. Thus, the effects of periparturient disease and diet can be eliminated. The results of this study indicate that uterine involution and ovarian resumption are hastened by treatment with SHT. Taken together, the results of this study show that the Chinese herbal medicine SHT promotes uterine involution and ovarian activity in postpartum dairy cows.

The positive effects of SHT in postpartum animals may

Table 2. The effects of Sheng Hua Tang treatment on trial cows' intrauterine fluid volume and uterine tonicity

\begin{tabular}{|c|c|c|c|c|c|c|c|c|c|}
\hline \multirow{2}{*}{ Item } & \multirow{2}{*}{ Group } & \multicolumn{8}{|c|}{ Day postpartum } \\
\hline & & 7 & 10 & 13 & 16 & 19 & 22 & 25 & 28 \\
\hline \multirow{2}{*}{$\begin{array}{l}\text { Intrauterine } \\
\text { fluid volume } \\
\left(\mathrm{cm}^{3}\right)\end{array}$} & $\begin{array}{l}\text { Control } \\
(\mathrm{n}=10)\end{array}$ & $2.8 \pm 0.4$ & $2.8 \pm 0.4$ & $2.3 \pm 0.8$ & $1.1 \pm 1.0$ & $0.4 \pm 0.7$ & $0.2 \pm 0.4$ & 0 & 0 \\
\hline & $\begin{array}{l}\text { Shung Hua Tang } \\
\quad(\mathrm{n}=10)\end{array}$ & $2.2 \pm 0.8^{*}$ & $2.0 \pm 0.9 *$ & $1.2 \pm 0.6^{* *}$ & $0.7 \pm 0.6$ & 0 & 0 & 0 & 0 \\
\hline \multirow[t]{2}{*}{$\begin{array}{l}\text { Uterine } \\
\text { tension score }\end{array}$} & $\begin{array}{l}\text { Control } \\
(\mathrm{n}=10)\end{array}$ & $3.0 \pm 0.0$ & $2.6 \pm 0.5$ & $2.2 \pm 0.6$ & $1.8 \pm 0.6$ & $1.5 \pm 0.5$ & $1.1 \pm 0.3$ & $1.1 \pm 0.3$ & $1.0 \pm 0.0$ \\
\hline & $\begin{array}{l}\text { Shung Hua Tang } \\
\qquad(\mathrm{n}=10)\end{array}$ & $2.8 \pm 0.4$ & $2.5 \pm 0.5$ & $1.9 \pm 0.3$ & $1.4 \pm 0.5$ & $1.0 \pm 0.0 * *$ & $1.0 \pm 0.0$ & $1.0 \pm 0.0$ & $1.0 \pm 0.0$ \\
\hline
\end{tabular}

* Means differ significantly between groups $(\mathrm{p}<0.05)$. ** Means differ significantly between groups $(\mathrm{p}<0.01)$.

Table 3. The effects of Sheng Hua Tang treatment on trial cows' first ovulation periods

\begin{tabular}{|c|c|c|c|c|c|c|c|c|c|}
\hline \multirow{2}{*}{ Item } & \multirow{2}{*}{ Group } & \multicolumn{8}{|c|}{ Day postpartum } \\
\hline & & 7 & 10 & 13 & 16 & 19 & 22 & 25 & $\geq 28$ \\
\hline \multirow[t]{2}{*}{$\begin{array}{l}\text { First ovulation } \\
(\%)\end{array}$} & $\begin{array}{l}\text { Control } \\
(\mathrm{n}=10)\end{array}$ & 0 & 0 & 10 & 10 & 20 & 0 & 0 & 60 \\
\hline & $\begin{array}{l}\text { Shung Hua Tang } \\
\qquad(\mathrm{n}=10)\end{array}$ & 0 & 0 & 10 & 40 & 10 & 0 & 10 & 30 \\
\hline
\end{tabular}


be explained by the known pharmacological actions of the five different ingredients used in preparing SHT. These ingredients include angelicae polysacchride, ligustazing, semen persicae, glycyrrhizae radix, and ginger constituents. Angelicae polysacchride, a polysacchride isolated from Radix Angelicae Sinensis, may stimulate the microenvironment within the body, to accelerate the synthesis and secretion of hematopoietic regulation factors. These effects of angelicae polysacchride had been studied and confirmed at the level of gene and protein expression (Wang et al., 1996; Wang et al., 2004; Li et al., 2005). Ligustrazing, one of the active components of the Ligustici Rhizoma, functions by promoting blood circulation and removing blood stasis (Liu et al., 2005). Semen Persicae was shown to possess anti-thrombotic effects (Wang et al., 2002). Glycyrrhizae Radix acts as a potent antispasmodic through the inhibition of phosphodiesterase 3 (Sato et al., 2006). And finally, ginger constituents, extracted from Zingiberis Rhizoma, may reduce inflammation by interfering with the inflammatory cascade (Chrubasik et al., 2005). Although SHT can trigger beneficial pharmacological effects in postpartum dairy cows, further investigations are needed to study the actual molecular mechanisms that triggered these effects.

\section{ACKNOWLEDGEMENTS}

The authors would like to thank the Council of Agriculture of Taiwan for supporting the research.

This work was supported by the Council of Agriculture, Executive Yuan, Taiwan, ROC.

\section{REFERENCES}

Benmrad, M., and J. S. Stevenson. 1986. Gonadotropin releasing hormone and prostaglandin $\mathrm{F}_{2 \alpha}$ for postpartum dairy cows: estrous, ovulation and fertility traits. J. Dairy Sci. 69:800-811.

Bensky, D., and R. Barolet. 1993. Chinese herbal medicine: formulas and strategies. Eastland Press. Inc., Seattle, WA.

Bondurant, R. H. 1999. Inflammation in the bovine female reproductive tract. J. Anim. Sci. 77(Suppl. 2):101-110.

Cao, L. Q. 2008. 46 cases of early incomplete abortion by the drug treatment of decoction for puerperal blood stasis combined with powder for dissipating blood stasis. J. Liaoning College Tradit. Chin. Med. 10:84.

Chuang, C. H., P. J. Chang, W. S. Hsieh, Y. J. Tsai, S. J. Lin, and P. C. Chen. 2009. Chinese herbal medicine use in Taiwan during pregnancy and the postpartum period: a population-based cohort study. Int. J. Nurs. Stud. 46:787-795.

Chrubasik, S., M. H. Pittler, and B. D. Roufogalis. 2005. Zingiberis rhizoma: a comprehensive review on the ginger effect and efficacy profiles. Phytomedicine 12:684-701.

Darwash, A. O., G. E. Lamming, and J. A. Wooliams. 1997. The phenotypic association between the interval to postpartum ovulation and traditional measures of fertility in dairy cattle.
Anim. Sci. 65:9-16.

Dohmen, M. J. W., J. A. C. M. Lohuis, G. Huszenicza, P. Nagy, and M. Gacs. 1995. The relationship between bacteriological and clinical findings in cows with subacute/chronic endometritis. Theriogenology 43:1379-1388.

Gajewski, Z., and R. Faundez. 1992. Characteristics and analysis of the uterus electrical activity in the pregnant cow. Theriogenology 37:1133-1145.

Gajewski, Z., R. Thun, R. Faundez, and Z. Boryezko. 1999. Uterine motility in the cow during puerperium. Reprod. Domest. Anim. 34:185-191.

Galbreath, C. W. 2008. Effect of feeding flax or linseed meal on progesterone clearance rate in ovariectomized ewes. Domest. Anim. Endocrinol. 35:164-169.

Gier, H. T. and G. B. Marion. 1968. Uterus of the cow after parturition: involution changes. Am. J. Vet. Res. 29:83-96.

Gilbert, R. O., W. T. K. Bosu, and A. T. Peter. 1990. The effect of Escherichia coli endotoxin on luteal function on Holstein heifers. Theriogenology 33:645-651.

Ginther, O. J. 1998. Ultrasonic imaging and animal reproduction: cattle. Equiservices, USA.

Hirsbrunner, G., B. Knutti, I. Liu, U. Ku, G. Scholtysik, and A. Steiner. 2002. An in vivo study on spontaneous myometrial contractility in the cow during estrus and diestrus. Anim. Reprod. Sci. 70:171-180.

Ho, M., T. C. Li, and S. Y. Su. 2011. The association between traditional Chinese dietary and herbal therapies and uterine involution in postpartum women. Evid. Based. Complement. Alternat. Med. 2011:1-9.

Hong, M., L. Yu, C. Ma, and Q. Zhu. 2003. Effect of extract from shenghua decoction on myoelectric activity of rabbit uterine muscle in the latest period of pregnancy. Zhongguo Zhong Yao Za Zhi. 28:1162-1164.

Hu, H., B. Hang, and P. Wang. 1991. Anti-inflammatory effect of Radix Angelicae Sinensis. China J. Chin. Materia Med. 16:684-686.

Hussain, A. M., and R. C. W. Daniel. 1991. Bovine endometrites: current and future alterative therapy. J. Vet. Med. 38:641-651.

Huszenicza, G., S. Jánosi, M. Kulcsár, P. Kóródi, J. Reiczigel, L. K'atai, A. R. Peters and F. De Rensis. 2005. Effects of clinical mastitis on ovarian function in postpartum dairy cows. Reprod. Domest. Anim. 40:199-204.

Kawahima, C., E. Kaneko, C. A. Montoya, M. Matsui, N. Yamagishi, N. Matsunaga, M. Ishii, K. Kida, Y. I. Miyake, and A. Miyamoto. 2006. Relationship between the first ovulation within three weeks postpartum and subsequent ovarian cycles and fertility in high producing dairy cows. J. Reprod. Dev. 52:479-486.

Kindahl, H., M. Banaka, K. Kask, K. Konigsson, H. Gustafsson,, and K. Odensvik. 1999. Endocrine aspects of uterine involution in the cow. Reprod. Domest. Anim. 34:261-268.

Li, J., and Y. P. Wang. 2005. Effect of angelica polysaccharide on bone marrow macrophage and its relationship to hematopoietic regulation. Chin. Tradit. Herbal Drugs 36:69-72.

Lindell, J. O., H. Kindahl, L. Jansson, and L. E. Edqvist. 1982. Post-partum release of prostaglandin F2 $\alpha$ and uterine involution in the cow. Theriogenology 17:237-245.

Liu, J. G., F. Q. Xu, D. Z. Shi, and G. J. Dong. 2005. Effect of the extracts from Rhizoma Chuanxiong and Radix Paeouiae Rubra 
in different proportions on promoting blood circulation and removing blood stasis. Tradit. Chin. Drug Res. Clin. Pharmacol. 16:315-317.

Mateus, L., L. Lopes da Costa, H. Carvalho, P. Serra and J. Robalo Silva. 2002. Blood and intrauterine leukocyte profile and function in dairy cows that spontaneously recovered from postpartum endometritis. Reprod. Domest. Anim. 37:176-180.

Melendez, P., J. McHale, J. Bartolome, L. F. Archbald, and G. A. Donovan. 2004. Uterine involution and fertility of holstein cows subsequent to early postpartum PGF $2 \alpha$ treatment for acute puerperal metritis. J. Dairy Sci. 87:3238-3246.

National Research Council. 1989. Nutrient requirements of dairy cattle. National Academy Press. Washington, DC.

Okano, A., and T. Tomizuka. 1987. Ultrasonic observation of pospartum uterine involution in the cow. Theriogenology 27:369-376.

Opsomer, G., Y. T. Grohn, J. Hertl, M. Coryn, H. Deluyker, and A. de Kruf. 2000. Risk factors for postpartum ovarian disfunction in high producing dairy cows in Belgium: a field study. Theriogenology 53:841-857.

Paape, M. J., C. Desjardins, W. D. Schultze, and J. W. Smith. 1972. Corticosteroid concentrations in jugular and mammary vein blood plasma of cows after overmilking. Am. J. Vet. Res. 33:1753-1758.

Paisley, L. G., W. D. Mickelsen, and P. B. Anderson. 1986. Mechanisms and therapy for retained fetal membranes and uterine infections of cows: a review. Theriogenology 25:353381.

Peter, A. T., and W. T. K. Bosu. 1987. Effects of intrauterine infection on the function of the corpora lutea formed after first postpartum ovulation in dairy cows. Theriogenology 27:593600

Roch, J. F., D. Mackey, and M. D. Diskin. 2000. Reproductive management of postpartum cows. Anim. Rerprod. Sci. 60:703712

SAS Institute. 2002. Statistics User Guide. Version9. SAS Inst., Inc., Cary, NC. 4149-4172.

Sato, Y., T. Akao, J. X. He, H. Nojima, Y. Kuraishi, T. Morota, T. Asano and T. Tani. 2006. Glycycoumarin from Glycyrrhizae Radix acts as a potent antispasmodic through inhibition of phosphodiesterase 3. J. Ethnopharmacol. 105:409-414.
Sheldon, I. M., A. N. Rycroft and C. Zhou. 2004. Association between postpartum pyrexia and uterine bacterial infection in dairy cattle. Vet. Record. 154:289-293.

Sheldon, I. M., D. E. Noakes and H. Dobson. 2002. Effect of the regressing corpus luteum of pregnancy on ovarian folliculogenesis after parturition in cattle. Biol. Reprod. 66:266-271.

Slama, H., D. Vaillancourt, and A. K. Goff. 1991. Pathophysiology of the puerperal period: Relationship between prostaglandin $\mathrm{E} 2\left(\mathrm{PGE}_{2}\right)$ and uterine involution in the cow. Theriogenology 36:1071-1090.

Stevenson, J. S. 1997. Clinical reproductive physiology of the cow. In Current Therapy in Large Animal Theriogenology (Ed. R. S. Youngquist) pp. 257-267. W. B. Saunders Co., Philadelphia, PA, USA.

Thatcher, W. W., and C. J. Wilcox. 1973. Physiological, environmental, and hormonal factors at insemination which may affect conception. J. Dairy Sci. 56:873-877.

Wang, J., X. Y. Xia, R. X. Peng, and X. Chen. 2004. Activation of the immunologic function of rat Kupffer cells by the polysaccharides of Angelica sinensis. Acta Pharmaceutica Sinica 39:168-171.

Wang, N., Q. Liu, D. Peng, L. Wang, and S. Wang. 2002. Experimental study on anti-thrombus effect of different extracts from Semen Persicae. Zhong Yao Cai 25:414-415.

Wang, Y., and B. Zhu. 1996. The effect of Angelica polysaccharide on proliferation and differentiation of hematopoietic progenitor cell. Chin. Med. J. 76:363-366.

Youngquist, R. S., and M. D. Shore. 1997. Postpartum uterine infection. In: Current Therapy in Large Animal Theriogenology (Ed. R. S. Youngquist) pp. 335-340. W. B. Saunders Co., Philadelphia, PA, USA.

Zhao, D., W. H. Zhan, L. H. Li, F. Z. Nie, J. J. Jiao, and Y. Li. 2006. Effects of different concentration extract from Shenghua decoction on contractile activity of the uterine smooth muscle isolated from normal, estrogen-treated and postpartum mice. Zhongguo Zhong Yao Za Zhi. 31:243-246.

Zhao, F. Y., X. P. Cui, J. B. Yang, and Y. C. Yang. 2008. Effects of "shenghua decoction" on hemorrhage and menstrual restoration following drug-induced abortion. Shanghai J. Tradit. Chin. Med. 42:57-58. 